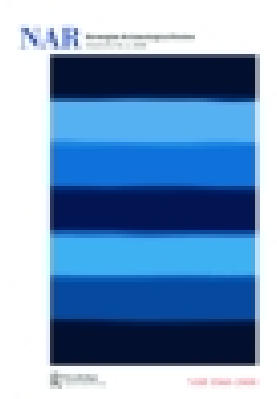

Norwegian Archaeological Review

ISSN: 0029-3652 (Print) 1502-7678 (Online) Journal homepage: http://www.tandfonline.com/loi/sarc20

\title{
From Artefact Biographies to 'Multiple Objects': A New Analysis of the Decorated Plaques of the Irish Sea Region
}

\section{Andrew Meirion Jones, Marta Díaz-Guardamino \& Rachel J. Crellin}

To cite this article: Andrew Meirion Jones, Marta Díaz-Guardamino \& Rachel J. Crellin (2016): From Artefact Biographies to 'Multiple Objects': A New Analysis of the Decorated Plaques of the Irish Sea Region, Norwegian Archaeological Review, DOI: 10.1080/00293652.2016.1227359

To link to this article: http://dx.doi.org/10.1080/00293652.2016.1227359

曲 Published online: 24 Oct 2016.

Submit your article to this journal $\pi$

Q View related articles ¿

View Crossmark data $₫$ 


\title{
From Artefact Biographies to 'Multiple Objects': A New Analysis of the Decorated Plaques of the Irish Sea Region
}

\author{
Andrew Meirion Jones, Marta Díaz-Guardamino and Rachel J. Crellin
}

\begin{abstract}
The concept of artefact biographies is well established, but has received increasing criticism from archaeologists and anthropologists. This article reviews this concept and its critiques from the basis of a new digital analysis (using reflectance transformation imaging) of a small group of decorated Neolithic artefacts from the Isle of Man and north Wales: stone plaques. We argue that the plaques are best understood as being situated in diverse and changing networks of relationships because they are altered over time. To adequately comprehend the changes undergone by these remarkable artefacts it is important that we highlight the ontological character of these changes. To this end we argue that, rather than possessing cultural biographies, these artefacts are best described as being 'multiple objects'.
\end{abstract}

\section{INTRODUCTION}

The concept of the cultural biography of artefacts is now well established in prehistoric archaeology. Since the concept of artefact biographies was first discussed (Bradley and Edmonds 1993, Thomas 1996, Tilley 1996, Gosden and Marshall 1999) the idea has been re-evaluated, critiqued (Shanks 1998, Holtorf 2008, Joy 2009, Burström 2014) and modified (Joyce and Gillespie 2015). In this article we retain the insight that mapping the changes to an artefact over an extended duration offers a powerful analytical tool (see Schiffer [1972, 1976] for the earliest discussion of this concept). However, we argue that maintaining the metaphorical descriptor 'biography' muddies our understanding of the complexities involved in the changes undergone by prehistoric artefacts. As an alternative we introduce the concept of the 'multiple object', which places emphasis on the ontological complexities that artefacts undergo as they alter and change. We discuss these ideas focusing on a specific set of artefacts: the decorated plaques of the Isle of Man, an island located in the Irish Sea region of the British Isles.

\section{SLATE ARTEFACTS, AND THE NEOLITHIC OF THE ISLE OF MAN}

Artefacts of metamorphic rock - slates and schists - are a common feature of the prehistory of a number of regions in Europe. Slate knives are distinctive artefacts in the Mesolithic of Fennoscandia, and are traded

Andrew Meirion Jones, Department of Archaeology, University of Southampton, Southampton, UK.

Marta Díaz-Guardamino, Department of Archaeology, University of Southampton, UK.

Rachel J. Crellin, School of Archaeology and Ancient History, University of Leicester, Leicester, UK. E-mail: amj@soton.ac.uk 
north to south across the boundaries between hunter-gatherers and farmers (Hallgren 2008, 2012), while schist plaques are a feature of Late Neolithic and Chalcolithic mortuary practices in Portugal and Spain (Gonçalves 2008, Lillios 2008). Slates and schists lend themselves to decoration, as is the case for both Mesolithic Scandinavia and Copper Age Iberia. In this article we examine an unusual group of decorated slate artefacts from the Isle of Man.

The Isle of Man, situated in the centre of the Irish Sea (Fig. 1), sits apart geographically and culturally from the British and Irish Neolithic sequences. The distinctiveness of the Manx Neolithic was debated in the early years of the 20th century (Clark 1935), but it was not until a series of remarkable excavations during the war years in advance of the extension of Ronaldsway airport (Bruce et al. 1947), in the south of the island, and at the multi-period site of Ballateare (Bersu 1947) in the north of the island, that an island-wide late Neolithic culture came to be defined.
The material signatures of this Neolithic culture included a distinctive class of tall round-based earth-fast jars, known as Ronaldsway jars, sometimes found associated with small decorated Grooved Ware vessels. Other distinctive artefacts include roughened truncated butt (RTB) axes, hump-backed scrapers, lozenge-shaped arrowheads and the decorated slate plaques that are the focus of this paper (Fig. 2). The 'Ronaldsway culture' was later designated by Piggott (1954, pp. 347-351) as one of his secondary Neolithic cultures: argued to be a development of an initial wave of Neolithic cultural activity beginning in southern England and diffusing to 'peripheral' regions, such as the Isle of Man.

The five slate plaques, deposited in a group at the back of the Neolithic "house" at Ronaldsway (Bruce et al. 1947), have remained a curiosity since their excavation. The plaques are notable for their small size and relative delicacy. Decoration is documented on two of these plaques. Since the
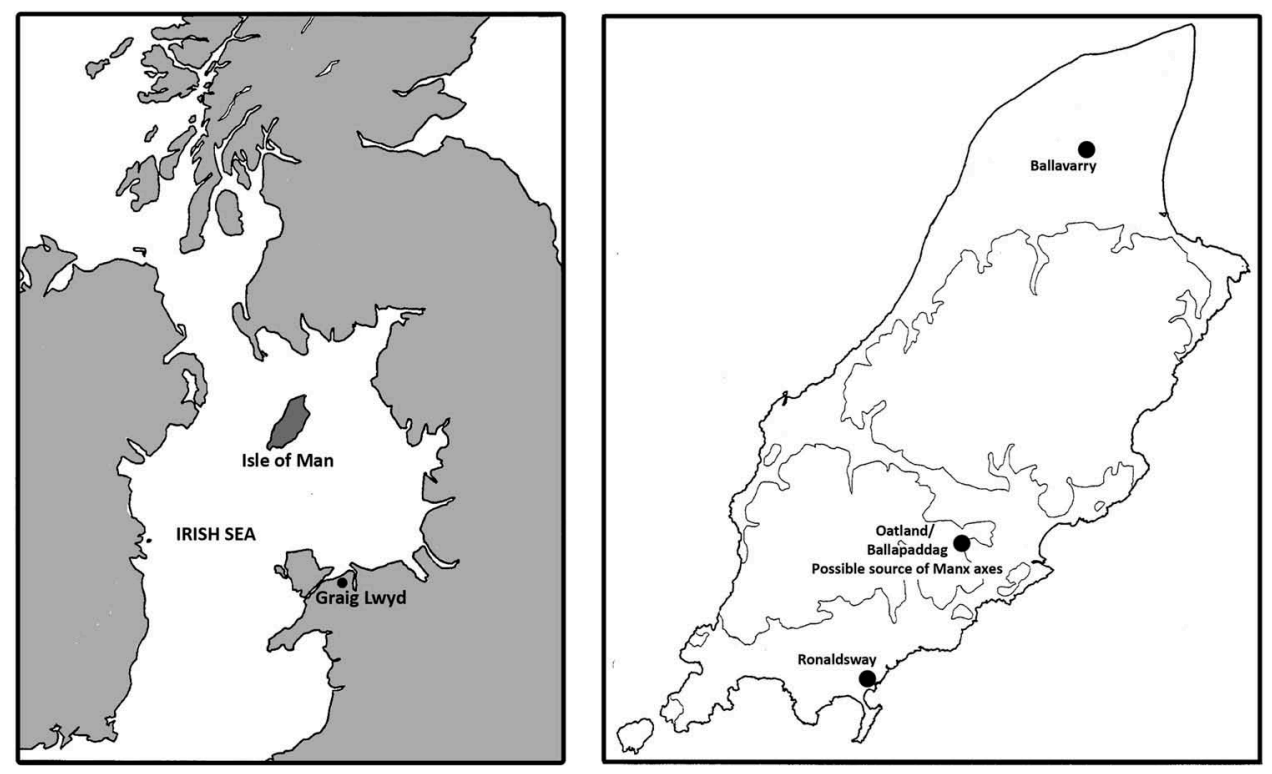

Fig. 1. Map of Irish Sea region locating the Isle of Man and Graig Lwyd, north Wales. Detailed inset of Isle of Man with locations of Ronaldsway, Ballavarry and OatlandlBallapaddag. Image: Hannah Sackett after images in Burrow (1997). 

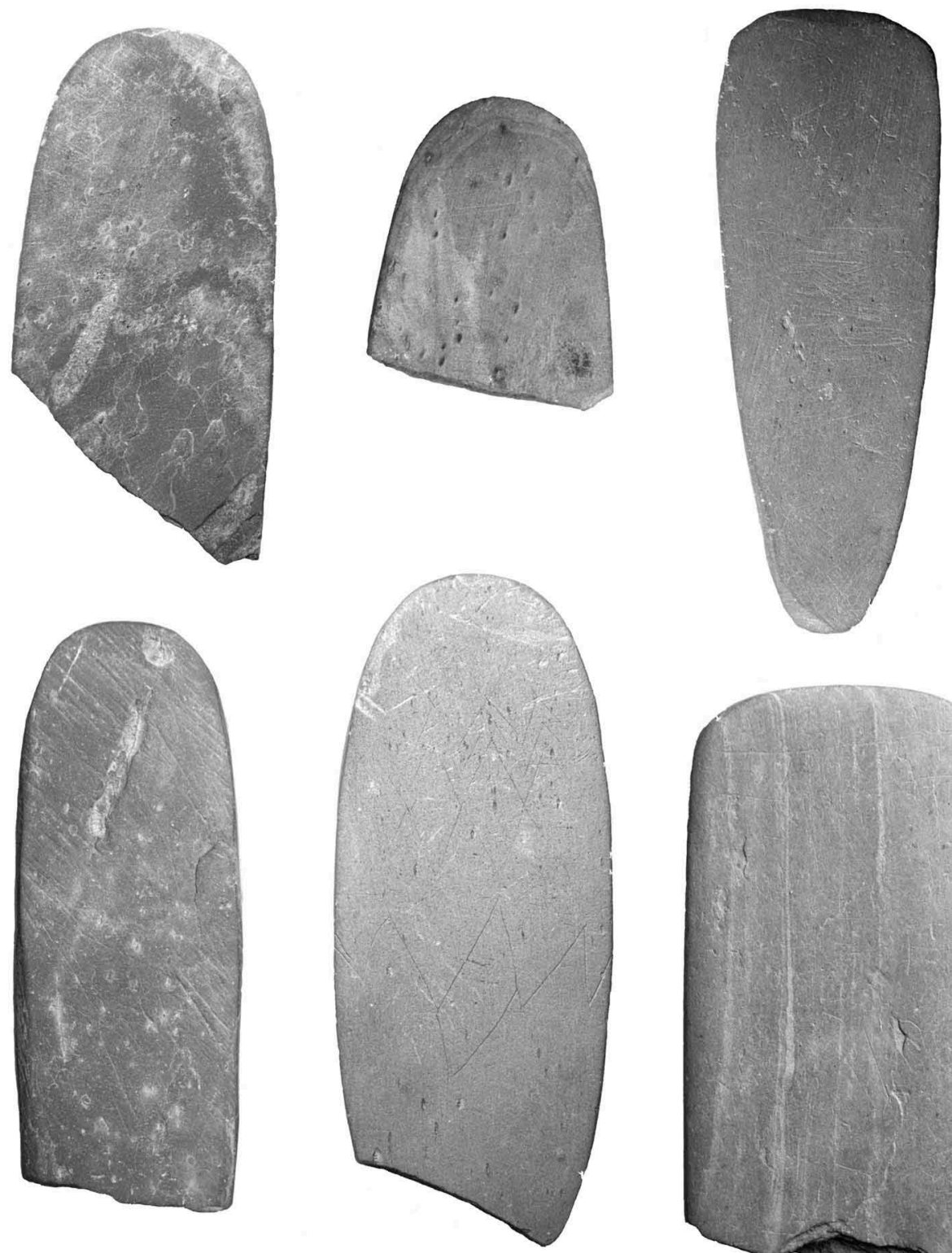

$\mathrm{cm}$
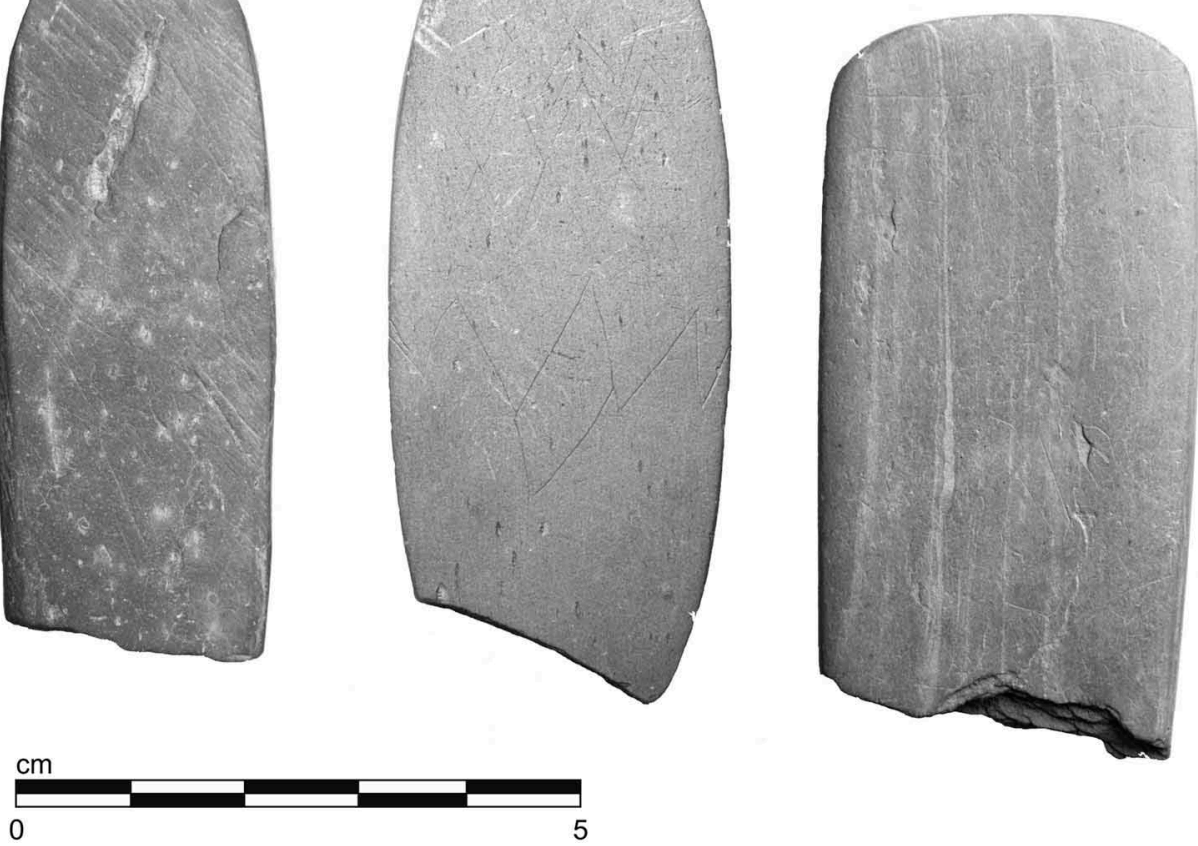

Fig. 2. The group of slate plaques from the Isle of Man. Photograph: Marta Díaz Guardamino.

1940s a further decorated plaque has been excavated from a pit site at Ballavarry (Garrad 1984). The plaques routinely appear in accounts of the Manx Neolithic (Bruce et al. 1947, Piggott 1954, Burrow 1997, Crellin 2014), although their function and 
associations remain enigmatic. Most authors mention the close resemblance between the decoration on the plaques and that on Grooved Ware vessels. For example, Burrow (1997, p. 21) notes a resemblance between the decoration of the Ballavarry plaque and a Grooved Ware vessel from Glencrutchery, and discusses the wider currency of these designs across pottery and stone artefacts.

Accelerator Mass Spectrometry (AMS) radiocarbon dates from a suite of Ronaldsway sites which established that the Ronaldsway culture was a phenomenon of the 3rd millennium BC (Burrow and Darvill 1997). A more recent review of radiocarbon dates for the Ronaldsway Neolithic in Rachel Crellin's doctoral thesis concludes that calibrated dates for the Ronaldsway sites derive from between the $31 \mathrm{st}$ and $24 \mathrm{th} / 23 \mathrm{rd}$ centuries BC (Crellin 2014, p. 215), although the dates for Ballavarry and the Ronaldsway house site are situated towards the end of this period.

One of the problems that have hampered further interpretation of the plaques is the sheer difficulty of accurately recording the decoration on these small and delicate slate artefacts. Most researchers have tended to reproduce the documentation of Bruce et al. (1947) for Ronaldsway, or of Larch Garrad (1984) for Ballavarry. As part of a wider project concerned with the digital analysis of decorated artefacts from Neolithic Britain and Ireland (the 'Making a Mark: Imagery and Process in Neolithic Britain and Ireland' project, funded by the Leverhulme Trust) a new programme of documentation was made to alleviate this problem and to facilitate a consideration of these plaques in their wider regional and inter-regional contexts.

This article will discuss the method of digital documentation, and the results of this analysis. We will then discuss these results within a wider interpretative framework that examines their relationship to other stone tool types, especially polished stone axes. Following this discussion, the plaques will be compared with another example from the Irish Sea region - the plaque from Graig Lwyd, north Wales - and plaques from further afield in Iberia. We then utilise our findings as a means of widening our theoretical analysis to argue for a shift away from well-established accounts of cultural biographies to more ontologically focused discussions of the plaques as multiple objects.

\section{DIGITAL ANALYSIS OF THE MANX PLAQUES: METHODOLOGY}

As part of the Leverhulme Trust-funded 'Making a Mark' project the authors digitally recorded all five plaques from Ronaldsway and the single example from Ballavarry using reflectance transformation imaging (RTI). The RTI technique (Mudge et al. 2006) was developed in 2001 at Hewlett Packard Laboratories (Malzbender et al. 2001). RTI is a non-destructive, affordable and easy imaging technique. The technique was especially useful for recording the Manx plaques because of its ability to acquire and represent the $3 \mathrm{D}$ reflectance properties of objects. Reflectance transformation images provide increased realism, including surface colours, self-shadowing, sub-surface scattering and inter-reflections, in comparison with traditional texture mapping. The technique performs sampling and modelling of the reflectance function independently for each pixel, enabling the user to change the material properties of objects in the scene (Malzbender et al. 2004).

The Manx plaques were recorded using the highlight-based method (Mudge et al. 2006). A series of raking and oblique light images were captured with a Nikon D800e DSLR camera following Cultural Heritage Imaging guidelines (Cultural Heritage Imaging 2013a). The open-source RTI builder software, developed by the University of Minho in collaboration with Cultural Heritage Imaging in 2009, was used for processing, as described in the guide to highlight image processing (Cultural Heritage Imaging 2011). PTM and RTI files were viewed via specialised software, the RTI viewer (ISTI-CNR/ CHI RTIViewer) (Cultural Heritage Imaging 
2013b). This software enables interactive manipulation of the lighting position and enhancement of the final outcomes through different rendering modes.

\section{RESULTS OF THE DIGITAL ANALYSIS OF THE MANX PLAQUES}

The results of the digital analysis of the plaques highlight two key aspects of the analysis: the organisation of motifs, and evidence for erasure and reworking. We will discuss these in the following. The alphabetical system used for recording the plaques adopted by Bruce et al. (1947) is retained.

\section{ORGANISATION OF MOTIFS ON THE MANX PLAQUES}

The decoration on the plaques is characterised by fine scratch marks, likely to have been executed with a sharp flint implement on the basis of the fineness of the scratches. RTI analysis allows, for the first time, a clear picture of the organisation of these scratched motifs. The best-known decorated plaque is Ronaldsway plaque 'e' (illustrated by Bruce et al. 1947, Piggott 1954, p. 349, Burrow 1997, p. 30). The obverse side of this plaque clearly exhibits three registers of lozenge motifs running horizontally across its surface (Fig. 3A). The reverse of this plaque also has a register of parallel zig-zag motifs, and a further register of lozenge motifs below this (Fig. 3B).

Ronaldsway plaque ' $d$ ' is also decorated (Fig. 4). This is illustrated by Burrow (1997, p. 30). Curiously, it does not feature in the original site publication (Bruce et al. 1947), although it was recognised and is illustrated in the site archive. The decoration of this plaque is very difficult to discern in previous documentations, but using RTI it is possible to tell that the obverse is decorated with a register of widely spaced lozenges, near the base of the plaque (Fig. 4A). The reverse, meanwhile, is extensively decorated (Fig. 4B). The top of the plaque has a register of widely spaced zig-zags. These are obscured beneath grinding marks probably intended to remove this register of motifs (Fig. 4B, B-1 and B-2; see later discussion of these). Below this area of grinding is a register of widely spaced zig-zags. Just below that is a register of small, tightly spaced zigzags. Further below that is another register of large widely spaced zig-zags. Finally, near the base, is a further register of large widely spaced lozenges or 'butterfly' motifs (Fig. 4B).

The Ballavarry plaque (Garrad 1984) also has a distinctive series of decorations (Fig. 5). On the obverse of the plaque there are two horizontal incised lines making two distinct registers (Fig. 5A, A-1). Above and between these lines are a series of oblique incisions. At the midway point on the plaque we can discern the faint traces of two more evenly spaced horizontal incised lines - especially prominent to the left - with the possibility that the lower of these continues on to the right of the plaque. At the centre of these horizontal incised lines is an incised design resembling a Greek cross (Fig. 5A). On the reverse of the Ballavarry plaque, an incised zig-zag line bisects a horizontal incised line and forms a distinct register (Fig. 5B, B-1). Below this is a further horizontal incised zigzag. Mid-way down the plaque there is another register of decoration formed by two horizontal lines sandwiching a series of oblique lines (Fig. 5B, B-2). This register of motifs is cut by an oblique line just above (Fig. 5B).

\section{REWORKING AND ERASURE}

The RTI analysis enables us to discern the organisation of motifs on these plaques with a greater degree of clarity, and there is a notable emphasis on distinct registers of decoration. More interesting is the evidence provided by RTI for the reworking and erasure of motifs. We have already seen on the reverse of the Ballavarry plaque that the top incised zig-zag cuts over an incised horizontal line which crosses over another worn zig-zag, and that at the mid-way point two oblique lines cut across the register of motifs (Fig. 5B). The best evidence for erasure comes from the obverse side 


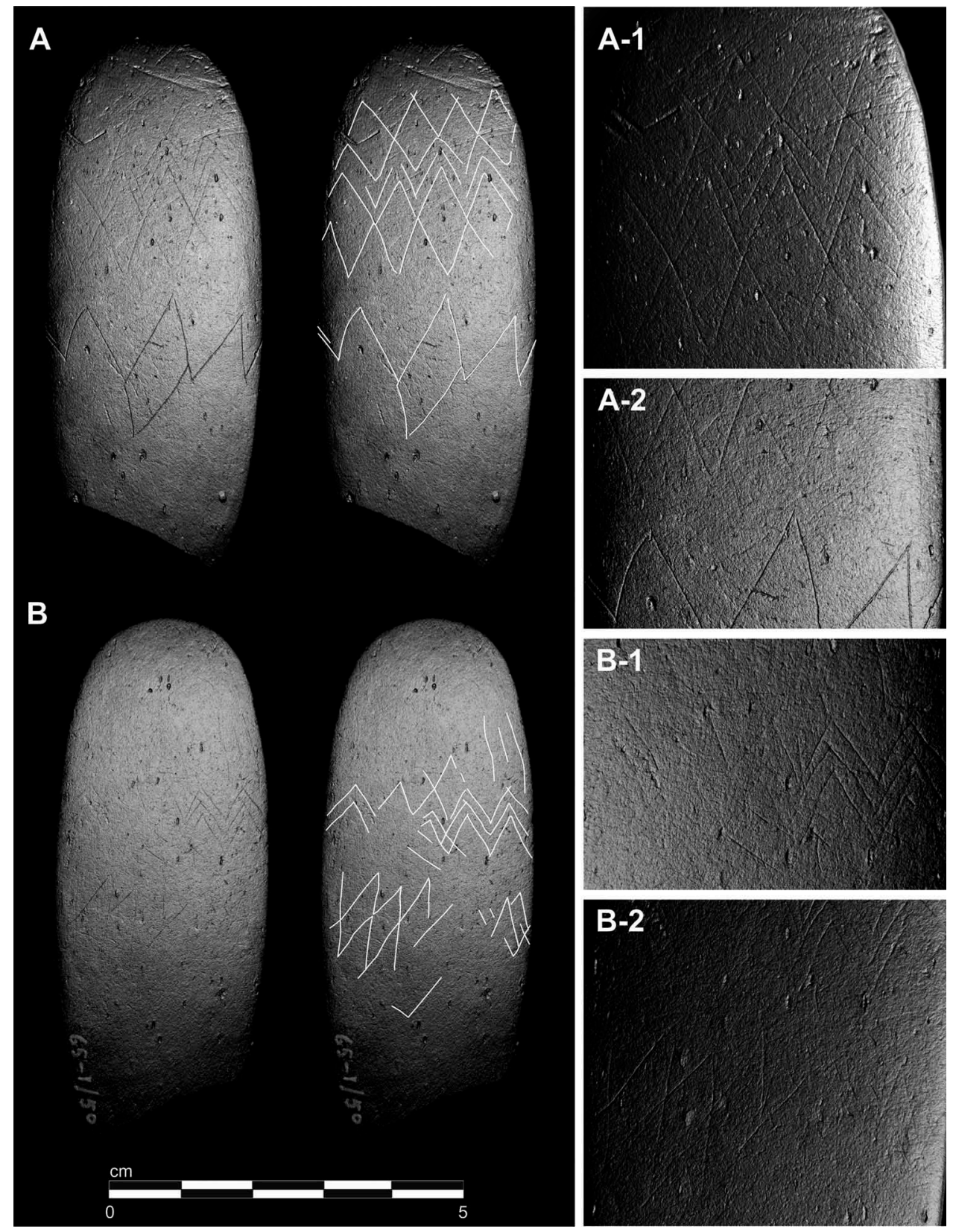

Fig. 3. Annotated RTI of Ronaldsway plaque 'e'. Obverse (A) and reverse (B). RTI image and annotation: Marta Díaz Guardamino.

of the Ballavarry plaque. Careful visual inspec- lines - shows that there are short incised vertition of the top register of motifs - formed by cal lines beneath the oblique lines two horizontal lines framing oblique incised (Fig. 5A, A-1). 

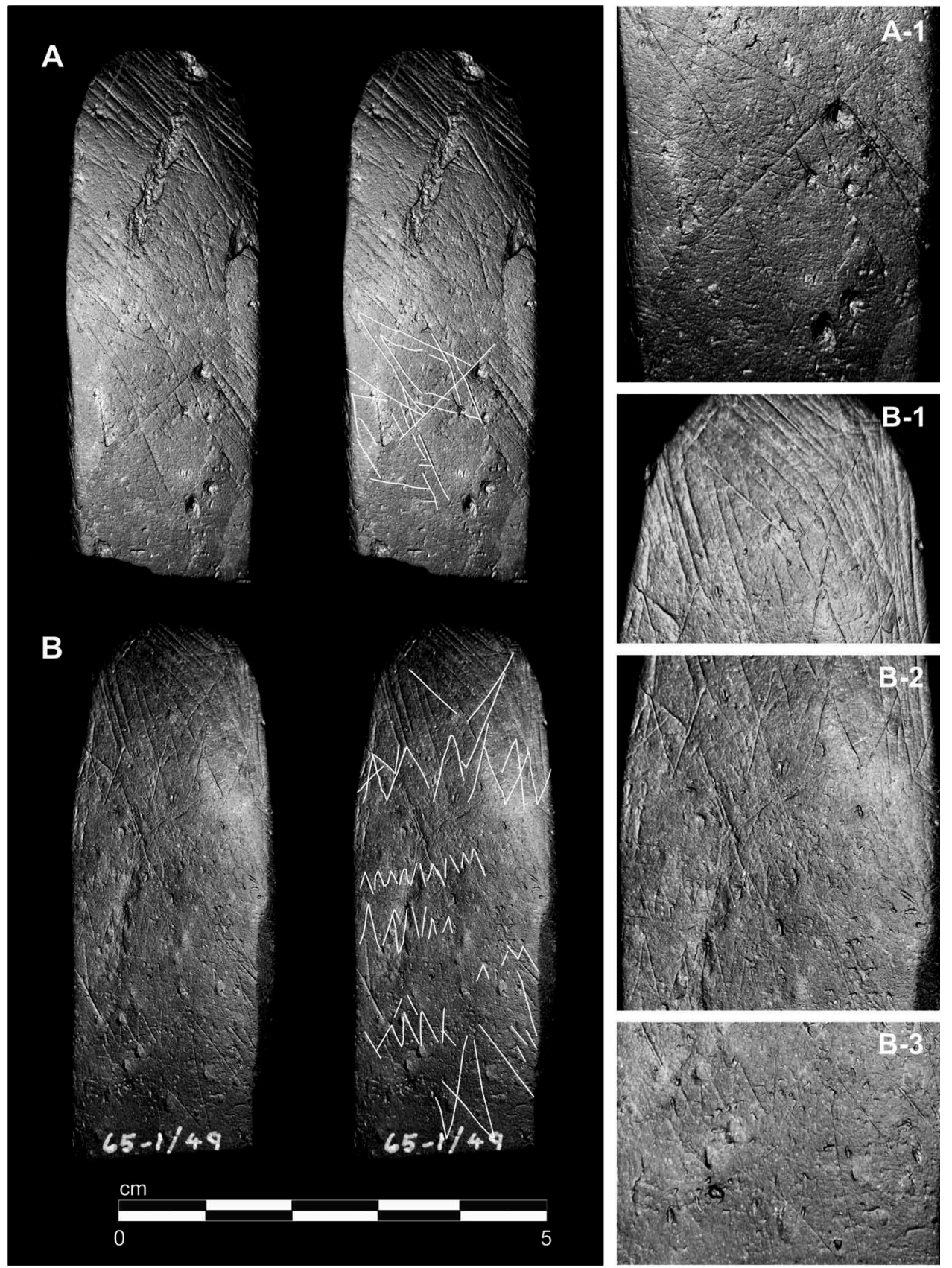

Fig. 4. Annotated RTI of Ronaldsway plaque 'd'. Obverse (A) and reverse (B). RTI image and annotation: Marta Díaz Guardamino.

On Ronaldsway plaque 'e' we can also clearly see on the obverse side that the lower register of lozenge motifs is more freshly incised than the upper motifs (Fig. 3A, A-2). In fact this was observed by Bruce and colleagues, who observe that 

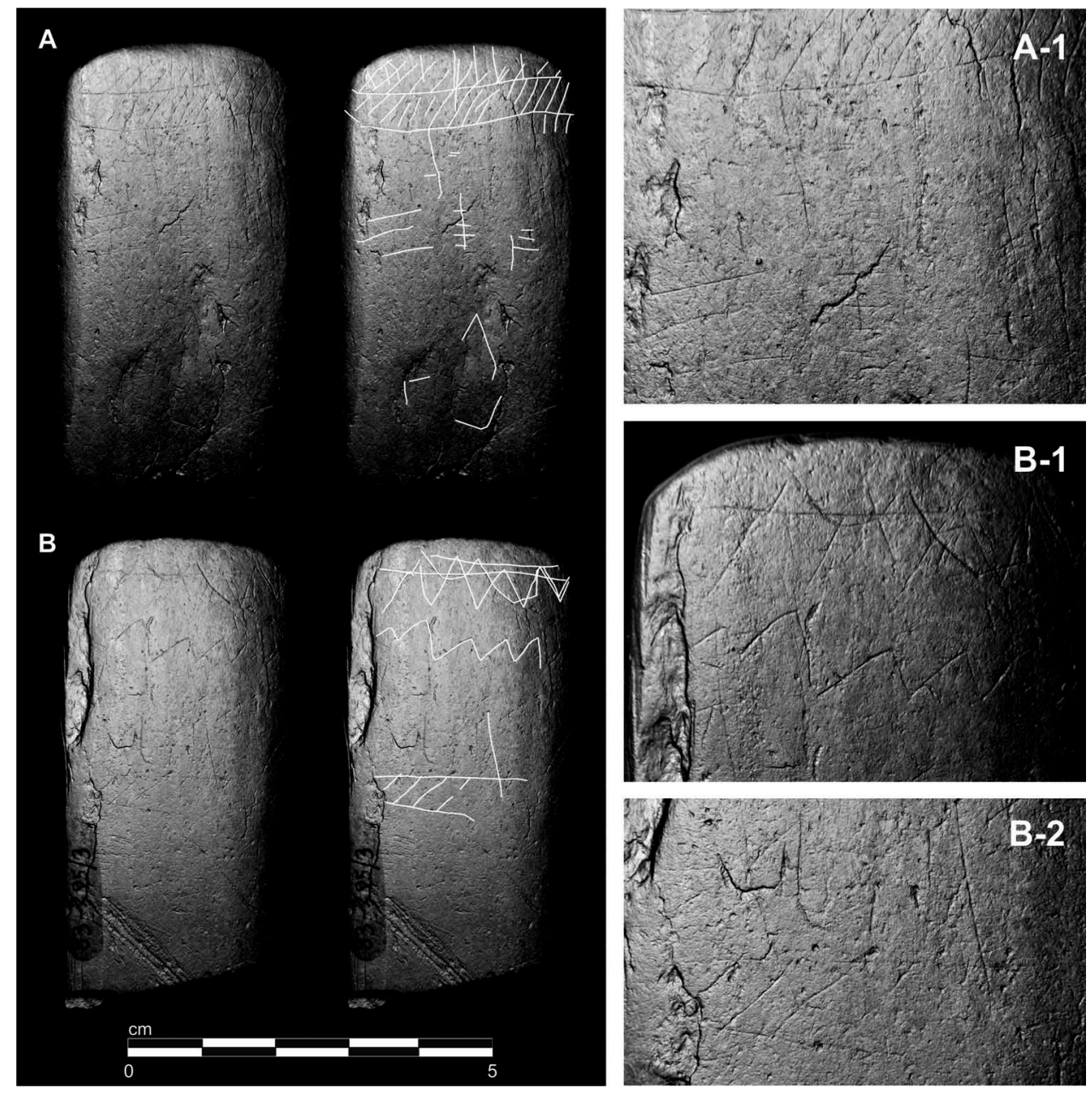

Fig. 5. Annotated RTI of Ballavarry plaque. Obverse (A) and reverse (B). RTI image and annotation: Marta Díaz Guardamino.

'the upper part of the ornament is more worn than the lowest row, which may have been scratched on later' (Bruce et al. 1947, p. 151).

Erasure is especially clear on the top of the reverse face of Ronaldsway plaque 'd'. Here a register of widely spaced zig-zags lies beneath, and is just visible through a cluster of grinding marks evidently meant to efface the motifs (Fig. 4B, B-2).

\section{MATERIAL EQUIVALENCES AND THE LIVES OF PLAQUES}

One of the notable features of the plaques is that of the six examples known from Ronaldsway and Ballavarry only one is intact, the remaining five are broken. The complete example, Ronaldsway plaque 'c', offers further insight into the significance of these artefacts because the plaque bears a close physical and material resemblance to a 
polished stone axe (Fig. 2, top right), having a wide 'blade' end and a pointed butt. The resemblance goes further than this, as the sides of the plaque are also facetted, a feature that is typical of group VI polished stone axes of Langdale type (Bradley and Edmonds 1993). Other than the possible source for stone axes in the Oatland/ Ballapaddag region on the Isle of Man (Barrs 2010), the Langdale source is the closest major stone axe source to the island (Crellin 2014, pp. 155-156). Added to this, RTI visualisation indicates that the blade end of Ronaldsway house plaque 'd' has marks of grinding (Fig. 4B, B-2), marks which may have been intended to erase decoration on the plaque surface. Again this is a technique common to the working of polished stone axes. Bruce et al. (1947, p. 12) note that the edges of some plaques have been worn to a 'sharp edge'.

Not all of the plaques bear an immediate resemblance to the classic profile of stone axes; many such as Ronaldsway plaque ' $\mathrm{e}$ ' bulge near the centre. However, an inspection of Manx polished stone axes indicates that this is a common feature of axes on the Isle of Man (see the axe illustrated in Bruce et al. 1947, plate XVIII, 'c'). In fact, Bruce et al. (1947, p. 12) remark on the 'celtiform' character of the intact plaque, while Piggott (1954, p. 350) goes so far as describing the plaque as an 'axe-amulet'. Curiously this feature of the plaques has not been remarked on by later generations of scholars.

All of this suggests that the plaques are intended to resemble miniature polished stone axes. Why, then, are so many of them broken? Clues to this come when we inspect the characteristic form of Manx stone axes: the RTB axes. These axes have a distinctive visual appearance, because the rough texture of the axe is 'broken' at the blade end by a section of polished surface, usually around the last quarter of the length of the axe. The Ronaldsway plaques are all broken to leave the shorter 'blade' section (e.g. Ronaldsway plaques ' $a$ ' and ' $b$ ') or are broken to leave the longer 'butt' end (e.g. Ronaldsway plaques ' $d$ ' and 'e', Ballavarry plaque). Notably it is the three artefacts broken at the 'butt' ends that are decorated. Plausibly, we might argue that decoration was a later stage in the lives of these artefacts.

Kate Barrs' (2010) analysis of the treatment of stone axes on the Isle of Man is significant here. Of the 191 stone axes in the Manx Museum collections, Barrs identifies 25 incomplete axes amongst the population of axes she studied ( $13 \%$ of the total). Of these, 13 were missing their butts, and 3 are missing their blade ends (Barrs 2010, pp. 34-35). Because of this damage it is not possible to say whether these axes are Manx RTB axes or axes from other geological sources, but this does suggest that the fragmentation of axes is a feature of the Manx Neolithic (Fig. 6). From the character of this fragmentation - clean breaks across the axe -
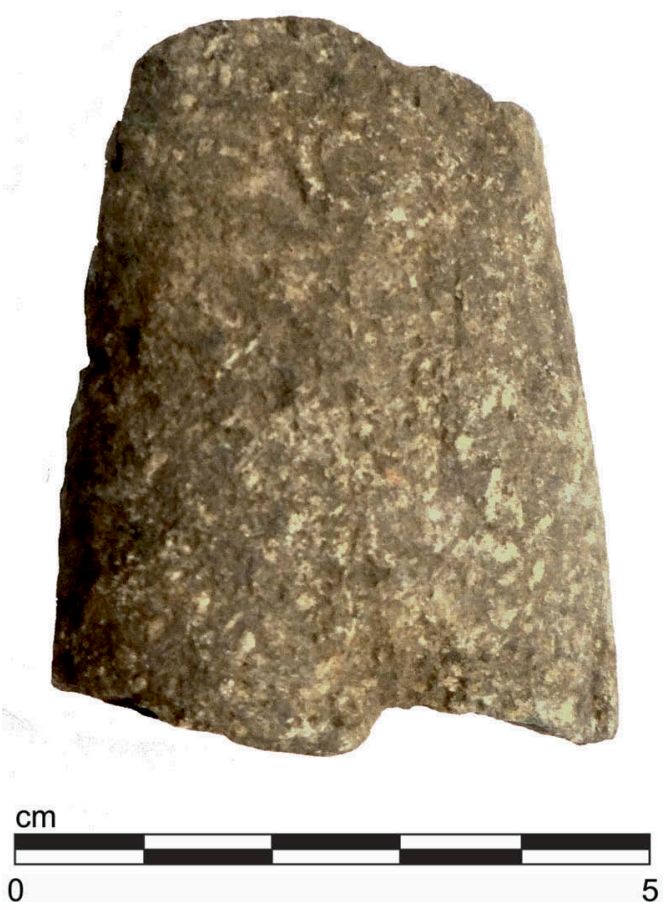

Fig. 6. Broken RTB axe from Ballacowin, Lonan, Isle of Man (find grid reference: SC 410 848). Photograph: Rachel Crellin. 
it seems likely that this is deliberate. Unfortunately we have insufficient evidence to be able to date this fragmentation to a specific period of the Neolithic, although the correspondence between the deliberate fragmentation of stone axes and the deliberate fragmentation of the plaques is very suggestive of a shared social practice.

Taking together the evidence from RTI analysis, added to macroscopic visual inspection of the plaques, suggests that we can begin to outline a rough life cycle for the plaques. The plaques are fashioned of slate (the Manx group of slates are abundant in the island; Burrow 1997, p. 3). They are shaped to resemble miniature stone axes. In some cases this shaping reproduces the working of stone axes, with grinding and sharpening around the blade. At some point in their lives the plaques were deliberately broken, just as was sometimes the case with stone axes. Visual inspection of all of the plaques indicates a clean break indicative of deliberate snapping in Ronaldsway plaques ' $b$ ', ' $d$ ' and ' $\mathrm{e}$ ' and the Ballavarry plaque. Ronaldsway plaque 'a' has a shear fracture, which may possibly have been accidental. Plaques are broken at a specific point, at a quarter of their length, producing a short 'blade' and a longer 'butt' fragment. Longer fragments are then decorated. We believe it is highly likely that decoration took place at this stage because the decorated areas avoid the broken ends of the plaque. It is evident that decorative motifs were not produced before the breakage because motifs do not cross the break. Decoration took the form of a restricted range of motifs (zig-zag, lozenges, linears) scratched on the surface in registers running horizontally across the plaque surface. Decoration was not the final act of working; in fact, in a number of cases decorative motifs were erased and replaced with fresh motifs. In the true sense of the word the plaques are palimpsests, with several phases of working and reworking erased on their surfaces. The use of slate to make these artefacts makes them especially amenable to reworking of this kind.

\section{PARALLEL PRACTICES IN THE IRISH SEA AND BEYOND}

We have identified a remarkable set of practices relating to the slate plaques of the Isle of Man, commencing with the manufacture of miniature artefacts, followed by deliberate and controlled fragmentation, the organisation of registers of motifs and the erasure and reworking of motifs in several phases of activity. The Manx plaques are few in number and almost unique in a British and Irish context. To what extent do they relate to other practices occurring in Britain and Ireland? This is easy to answer for the decorative motifs used on the plaques: they closely resemble the motifs used on Grooved Ware vessels and Orcadian settlement art. A number of previous commentators have made this link (Bruce et al. 1947, p. 12, Piggott 1954, p. 350, Burrow 1997, p. 21). Indeed Burrow (1999, pp. 134-136, Figure 5), goes further and suggests a link between the incised decoration on the rims and upper bodies of earth-fast pottery, Grooved Ware and the incised decoration on the plaques: the oblique lines on both sides of the Ballavarry plaque (Fig. 5A-1 and B-2) in particular can be linked with the decoration on sherds from Ronaldsway (Burrow 1999, Figure 5, Nos. 4 and 6). In addition, recent work by Darvill and Andrews (2014) suggests a further link between the plaques and the earth-fast pottery of the Isle of Man. Darvill and Andrews (2014) have identified the use of polychrome decoration on the surface of one earth-fast jar from Billown: a wavy line of black decoration used to separate an area of cream slip from the non-slipped buff-red surface of the rest of the vessel. Darvill and Andrews (2014, p. 537) draw a direct comparison between this painted wavy black line and the zig-zag decoration of the slate plaques. 
Another key parallel for the lozenge and zig-zag motifs found on the plaques are the incised motifs on the Cronk yn How standing stone, in the north of the Isle of Man (Darvill et al. 2005). This standing stone has a complex history and features incised decorations akin to that seen on the plaques (Darvill et al. 2005, pp. 291-294). Based on the activities associated with the Cronk yn How stone, the monument probably dates towards the end of the 3rd millennium $\mathrm{BC}$ and is therefore contemporary with the Manx plaques - although based on Darvill and colleagues' reconstruction of this monument, the lozenge and zigzag motifs would be running down the length of face A of the stone (Darvill et al. 2005, p. 290), rather than in registers running across as we observe with the Manx plaques. The carving of a cross motif on the surface of face A of this stone is also notable (Darvill et al. 2005 , p. 291) because a cross motif was identified on the obverse of the Ballavarry plaque, although this motif differs in its execution from the other motifs on the Cronk yn How stone being carved rather than incised and has been suggested to be a later Christian addition to the stone.

All in all the parallels in practice between the plaques and the Cronk yn How stone are striking: both the plaques and the Cronk yn How stone are composed of slate, and both are decorated with fine incised decorations and share common motifs. The decoration of the Cronk yn How stone with incised decoration is quite unusual for a monument of this type. Decoration of this kind is more commonly a feature of the early phases of decoration in the interior of passage tombs in Orkney and Ireland (O'Sullivan 1986, Eogan 1997, Bradley et al. 2001).

Miniature artefacts are also a feature of Irish passage tomb contexts, particularly miniature mace heads and carved stone balls (Herity 1974, pp. 126-129, Eogan 1986, pp. 142-144, Jones 2012, pp. 45-48), although miniature polished stone axes are uncommon in passage tomb contexts. Practices of carving and re-carving motifs are a significant feature of the interior of the major Irish passage tombs (O'Sullivan 1986, Eogan 1997, Jones 2004, Cochrane 2009). However, it should be noted that practices associated with the interior of passage tombs significantly pre-date the Manx plaques.

We can also observe practices of reworking in another decorated artefact from the Irish Sea region: the plaque from Graig Lwyd, Penmaenmawr, north Wales.

\section{THE GRAIG LWYD PLAQUE}

The Graig Lwyd plaque (Fig. 7) has had a chequered history. Excavated from floor B of the stone axe quarry at Graig Lwyd, north Wales (see Fig. 1 for location) by Hazzeldine Warren in 1921 (Warren 1921), the faintly incised motifs on the stone were disputed by the Keeper of the National Museum of Wales, W. F. Grimes (Grimes 1939), who regarded them as having a geological origin. Although Bruce et al. (1947, p. 12) regarded the plaque as a possible parallel for the Manx plaques, they were also cautious about its attribution. Other writers, including Breuil (1934), Hawkes (1941) and Piggott (1954, p. 290), regarded it as a genuine decorated Neolithic artefact.

RTI analysis of the plaque provides a clear visualisation of the motifs on the plaque, while also providing evidence for several phases of working. The motifs on the plaque are complex. The design consists of a number of shorter oblique incised lines forming a zigzag or chevron pattern, cross-cut by two oblique incised lines. It is evident that there are at least two phases of incised lines on the plaque, with deeper and longer incised lines cross-cutting shallower and shorter incised lines.

What is also evident is that this was not the last phase of activity. Cutting into the incised lines on the plaque is a large invasive flake that partially destroys part of the decoration. Further to this, the RTI analysis also clearly visualises a series of peck marks that are clearly cut into the incised motifs. 

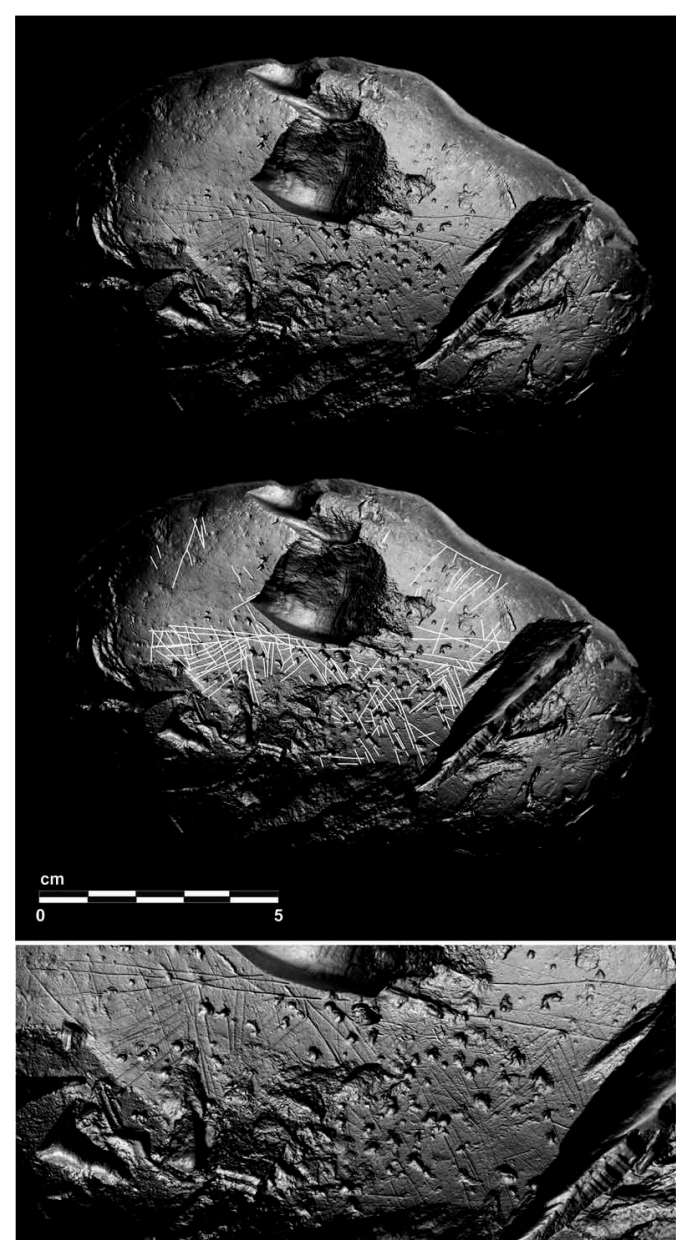

Fig. 7. Annotated RTI of Graig Lwyd plaque showing complete plaque and detail of decoration and damage on surface. RTI image and annotation: Marta Díaz Guardamino.

The major difference between Graig Lwyd and the Manx plaques is that the Graig Lwyd plaque is a chunky stone of rhyolite, rather than thin slate. However, there are clear parallels with the practices associated with the Manx plaques. The incised motifs are similar in appearance to those from Ronaldsway and Ballavarry, but the multiple phases of reworking and possible destruction also parallel the reworking we have identified on the Manx plaques. We also argued that the Manx plaques resemble miniature polished stone axes, and the Graig Lwyd plaque takes the form of a rough axe shape, or rough-out. Despite these parallels, a note of caution must be sounded. While we have a reasonable suite of dates placing the Manx plaques in the Late Neolithic, the Graig Lwyd plaque has not been dated so its chronological relationship to the Manx plaques is not certain. However, polished stone axes with their source in Graig Lwyd are known from the Isle of Man, indicating close exchange contacts around the Irish Sea region (Burrow 1997, Crellin 2014).

\section{IBERIAN CONNECTIONS}

We have examined a series of parallel practices in the Irish Sea region. We must now explore wider parallels in the Iberian Peninsula. The RTI analysis of the Manx plaques revealed the organisation of motifs into clear registers. Added to this we have suggested that the reworking of motifs is related to memorial practices.

The Iberian schist plaques, dated between c. $3500 / 3300$ and 2500. BC (Gonçalves 1999), seem to offer clear parallels to the Manx slate plaques. The motifs on the Iberian schist plaques are organised in clear registers (Gonçalves 2008), and one influential analysis argues that these registers are mnemonic devices for recording genealogies (Lillios 2008, pp. 170-176). Like the Manx examples, the Iberian schist plaques employ a restricted range of simple motifs (2008, pp. 38-72). Likewise the similarity between Iberian plaques and stone axes has been remarked upon (2008, pp. 117-121), just as we note equivalence between the Manx plaques and stone axes. Again, like the Manx examples there is evidence for complex life cycles for plaques, and the recycling of plaques (Oliveira 1993, Gonçalves et al. 2003, 2005a, 2005b, Lillios 2008, p. 110). In the Portuguese region of Alentejo, epicentre of the Iberian plaque tradition, there are numerous examples of recycled plaques. They were recut, their remaining decoration could be preserved or 
erased and new motifs could be incised. Plaque THE 1.79.134 from the tholos of Escoural is a good example of this. It was recut and shaped into a miniature plaque $(6 \mathrm{~cm})$, and the previous decoration on one of its sides was partially defaced, while it was decorated with new incised motifs on the other (Gonçalves et al. 2003, p. 228). Other interesting examples of recut and possibly purposefully fragmented plaques were collected from Anta 1 do Paço and Anta Grande do Zambujeiro (Gonçalves et al. 2003).

There are important differences between the Manx and Iberian plaques. Many of the Iberian plaques are perforated for suspension and wearing; this is not the case with the Manx plaques. The Iberian plaques are much larger, measuring between $8 / 10$ and 20/25 cm, while the Manx plaques are small, each measuring less than $10 \mathrm{~cm}$ in length. Another notable difference relates to the visibility of the motifs scratched on the plaques. Motifs are clearly visible on the surface of the Iberian plaques; in fact, Lillios (2008, pp. 141-169) goes so far as describing these as a writing system. This is not the case with the Manx examples; motifs are difficult to see on the surface of the plaques.

\section{FROM CULTURAL BIOGRAPHY TO \\ MULTIPLE OBJECTS: THE ONTOGRAPHY OF THE MANX PLAQUES}

How are we to understand the decorative practices relating to the Manx plaques? As we have argued, the Manx plaques have complex lives. It would be easy to describe these artefacts as having cultural biographies. The notion of cultural biography, derived from the anthropological analyses of Arjun Appadurai (1986), Igor Kopytoff (1986) and, latterly, Janet Hoskins (1998), has been translated into the theoretical lexicon of archaeology (Gosden and Marshall 1999). The notion of cultural biography has been immensely successful, quickly replacing the term 'use-life', derived from behavioural archaeology (Schiffer 1972, 1976, p. 191). The term 'cultural biography' seems to offer an intuitive and comprehensible concept for something that archaeologists have long recognised: the changing character of artefacts over time. Most significantly, the notion of cultural biography examines the way in which the lives of artefacts and the lives of people are closely entangled (Shanks 1998, Gosden and Marshall 1999). The term is not without its problems, however, and we hesitate to apply it here. Jody Joy (2009) notes that most artefact biographies in archaeology begin as they end their social or cultural lives; studies of prehistoric artefacts typically work backwards from their deposition or 'death' to their 'life'. Joy (2009, p. 543) also notes that many artefacts may have numerous lives and are situated in numerous relational networks. Likewise, objects may 'die' numerous times as they become part of and leave different relationships. Importantly the lives of objects may extend well beyond the human life cycle. How useful is the metaphor of 'biography' then if it is unable to capture the extended lives of artefacts? Should we perhaps retain Schiffer's notion of use-life which makes no assumptions about the metaphorical relationship between objects and people?

One of the clear advantages of the concept of a cultural biography of artefacts over the concept of 'use-life' is that it foregrounds the relational connections between objects and people: biographies change as artefacts shift from one network of relationships to another (Gosden and Marshall 1999, Joy 2009). We wish to retain this concept in our analysis of the Manx plaques: we argue that as they are worked and reworked they shift from one set of relational connections to another. A recent alternative to the cultural biography of artefacts has been proposed in the notion of object itineraries (Joyce 2015, Joyce and Gillespie 2015). The concept of object itineraries capture the extended narratives of objects lives, taking on board the critiques of artefact cultural biographies raised by Joy, discussed earlier: 
Examining object itineraries requires consideration of technologies for circulation; transformations that happen along the way; and the value of circulating objects for the production and reshaping of relations among humans, nonhumans and other forces. (Joyce 2015, p. 29)

Joyce discusses the case of Ulua marble vases, manufactured in Honduras between AD 500 and 1000. Despite being closely associated with the Ulua valley, Joyce argues that this is simply a single point in their itinerary (2015, p. 32). Examining things in terms of their itineraries frees us from thinking about them in place-bound terms.

We are attracted to these ideas, but this does not appear to serve the case of our plaques from the Isle of Man: so far as we know they did not leave the island and did not circulate widely. Their significance is derived from a series of alterations and reworking and revisions that took place over their lives. How, then, to discuss them?

\section{MULTIPLE OBJECTS}

One of the key problems with the notion of cultural biographies is that it imposes a familiar western ontological distinction on artefacts. Objects emerge as inert things (see Holtorf 2008) whose value and significance is bestowed on them as they pass from one set of relationships, or contexts, to another. As Bruno Latour (1993, pp. 94-95) points out, this is very much to argue from a constructivist position that sets up an asymmetry between the inert object and the active subject, or between nature and culture. For this reason we reject Nanouschka Burström's (2014) call for a humanistic perspective on artefact biographies. The notion of object use-lives (Schiffer 1972), while it circumvents the culturally imposed metaphor of 'biography', also treats objects as inert entities which exist for humans only in that they have a 'use'. Again this sets up an ontological distinction between inert objects and active subjects (see also Holtorf 2008). The notion of itineraries offers a more nuanced analysis of the relationships between human and nonhuman things and forces. We are persuaded by these ideas (see Díaz Guardamino 2015), particularly by the insight that things are in motion. We agree that things are in motion: they are in a constant state of becoming. While the notion of object itineraries importantly highlights this fact, it has less to say about the ontological insights resulting from a state of constant motion and change. This is something we wish to emphasise in our analysis of the Manx plaques. Rather than describing the Manx plaques as having complex cultural biographies, we prefer to say that the plaques are 'multiple objects'.

The notion of 'multiple objects' has resonances with Shanks' (1998, p. 15) point that people and things are symmetrical. Shanks uses the example of Gordon Childe excavating Skara Brae, Orkney. Childe's work brings Skara Brae into being. 'Is it not better to accept that the object world comes to be in our relationships with it?', Shanks (1998, p. 15) remarks. To discuss 'multiple objects' is to discuss the co-production of people and object. It is also to embrace Holtorf's (2008, p. 423) point that things are not stable over time: they are in a continual state of instability and becoming. That is why we describe them as multiple objects.

The concept of multiple objects requires some explanation. The notion of multiplicity and multiple objects was first raised by science studies scholar Anne-Marie Mol (2002) in her analysis of the treatment of lower-limb atherosclerosis (a disease of the arteries) at a Netherlands hospital. Through field analysis, Mol notes that the disease is produced in a number of locations: the clinic, pathology department, radiology department and so forth. The identification of the disease involves comparing patients able to walk with patients examined in surgery (Mol 2006). She concludes that the disease is not a single unified entity, but a multiple object: the atherosclerosis is enacted in multiple locations, and through multiple practices. It 
is a multiple object held together by these practices. Another example of the idea of multiplicity comes from human geographer Steve Hinchliffe (2010). Hinchliffe analyses a community garden project in Small Heath, Birmingham, UK. He notes that the garden is in fact three gardens: a garden run by a group of women; an urban garden, designated as such by the local council responsible for the Small Heath area of Birmingham; and a charity garden, funded by the National Lottery scheme. As Hinchliffe (2010, p. 304) points out, these three gardens are in some respects the same garden. The three gardens overlap in some senses, but they are shaped by different practices. The women's garden is shaped by people, worms, soil, weather and plants. The urban garden is shaped by local government plans and future policy. The charity garden is shaped by spreadsheets, statistics, targets and returns (Hinchliffe 2010, p. 305). Hinchliffe argues that these are not three views of the same garden, but three ways in which a garden is being made.

There is an important, and subtle, distinction between constructivist accounts of multiplicity and the notion of multiplicity we wish to argue for here. Constructivists would argue that the multiple garden results from different perspectives. This would be to argue for different representations of the same garden. Notice in this sort of account that the garden remains inert, and active subjects do the job of representing the garden. Along with Mol (2002) and Hinchliffe (2010) we would argue differently: if we focus on the practices of making the garden we realise that the garden is not simply being represented, it is being shaped - but crucially it is also involved in the shaping: as every gardener knows gardens do not stand still. They grow. The character of this growth partly depends on the actions of gardeners. The garden is both acting, and being enacted. It is the fact that it is simultaneously shaping and being shaped that makes it multiple. Here it is important to reiterate Shanks'
(1998, p. 15) point that 'the object world comes to be in our relationships with it'.

In fact archaeologists are already familiar with the concept of multiplicity in the form of the 'dividual' person. For some years now anthropologists and archaeologists have recognised the potential for persons to be composed of multiple relationships (for example, Strathern 1988, Chapman 2000, Thomas 2000, Fowler 2004, Jones 2005). Chris Fowler (2004, p. 8) provides the clearest discussion of these concepts: 'dividuals' describe a 'state of being in which the person is recognized as being composite and multiply-authored'. He goes on to state that 'the person is comprised of multiple features with different origins' (Fowler 2004, p. 8). Just as we conceptualise a single entity - a person to be composed of multiple and overlapping relationships, so too we argue that objects are also composed of multiple and overlapping relationships.

It is interesting that multiple persons have been readily accepted in anthropology and archaeology while the possibility of multiple objects has only emerged recently. We suspect that this asymmetry in approach relates to a more general asymmetrical distinction between supposedly active subjects and inert objects (for wider discussion of this point, see Olsen 2003, 2010, Ingold 2007, 2011). The notion of multiple objects has much in common with actor network approaches that treat objects and subjects symmetrically by examining how actions emerge from the relationships between things and people. Our aim in discussing multiple objects is twofold then: to emphasise that objects are composed of multiple relations, and to emphasise the symmetry between subjects and objects.

\section{THE MANX PLAQUES AS MULTIPLE OBJECTS}

We want to argue that the Manx plaques are best described as multiple objects in the same sense that Anne-Marie Mol describes atherosclerosis and Steve Hinchliffe describes the 
community garden in Small Heath, Birmingham. Rather than thinking of the Manx plaques as single unitary objects that moved through use-lives or cultural biographies during which different values were bestowed on them, we instead wish to argue that the plaques are multiple objects enacted by, and enacting, a series of differing practices. The notion of multiple objects shifts us away from ideas of representation, by which we mean the concept that there is an ontological distinction between knower and known, or subject and object. Instead we argue that the plaques are produced by, and produce, a series of connections - connections that link the properties of materials with bodies and senses (see also Conneller 2011). The advantage of considering the Manx plaques as multiple objects is that it forces us to analyse these connections and linkages with great care. Furthermore it prevents us from assuming that the plaques are simply local representations of larger forces (for fuller discussion of this, see Crellin 2014), and instead makes us consider how, and with what, connections are forged.

The Manx plaques are connective, they are made of the slate that forms much of the bedrock of the Isle of Man, and in form they are equivalent to polished stone axes of Langdale type. The form of local axes - the RTB axes - appears to form an important visual cue during their fragmentation. The very fragmentation of the plaques connects them to similar practices relating to stone axes. The motifs carved on their surfaces are also connective: they relate to motifs that are visible on Grooved Ware pottery, and on standing stone monuments, such as that at Cronk yn How. The organisation of motifs on their surfaces appears to link them to visual practices in Iberia, while the practices of marking and erasing echoes practices in north Wales and eastern Ireland. A host of practices associated with the plaques are also transformative. Plaques are transformed from slate into miniature axe forms, and they are then transformed by snapping or breaking them. After this they are decorated, and this decorative transformation continues. Decoration on the plaques is not concerned with visibility: decoration is not made visible. Instead decoration instantiates relationships - it connects to other decorative practices but decorative motifs fade quickly or are overwritten and erased. Decoration is an intimate practice meant to effect change.

The Manx plaques force us to think afresh about practices of visualisation. The motifs scratched on their surfaces are hardly visible, yet they contrast with other highly visible acts of visualisation, such as the decoration of Grooved Ware pottery, and the decoration of standing stones. Visual motifs on the plaques are not so much records, as they appear to be in pottery decoration and standing stones, so much as enactments: incising the plaques appears to do something, positioning the plaques in novel networks of relationships (for further analysis of this, see also Jones forthcoming) even if momentarily. The plaques emerge as a distinctive practice of intimate visual enactment: the visual enactment of change.

The Manx plaques are multiple objects precisely because they are composed of a series of different and overlapping relations. Critically, they are restless and changeable objects which do not appear to readily lend themselves to a single mode of understanding or representation. Like the other examples of multiple objects we have discussed, they both act and are enacted; slate is not an inert substance, marks on its surface fade rapidly, and the rock fractures easily. However, the properties of the slate depend very much on how it is worked and acted on. In the Isle of Man, slate may be used to make delicate plaques or substantial standing stones; the properties of slate are by no means 'set in stone'. The potential of slate is multiple; the properties elicited from the slate relate to how it is worked and marked (see also Conneller 2011). It is our argument that the different practices of working and decorating draw attention to, or elicit, the changeable character of the slate. 
Plaques are constitutive of a process of anchoring, of relating to the fabric of the island, while also being associated with processes of change. We wonder whether the plaques enact a distinctive kind of Manx ontology, associated simultaneously with constancy and change? Significantly this is an aspect of the archaeology of the Manx Late Neolithic and Early Bronze Age highlighted by Rachel Crellin (2014). The Isle of Man, with its distinctive archaeological record, acts as a nexus or fulcrum of relations of change and continuity, difference and similarity. The miniature plaques of the Isle of Man both distil and amplify multiple relational connections; relating simultaneously to the grand scale of the Cronk yn How stone, and the forms of polished stone axes, while also relating further afield to the Graig Lwyd plaque, with Irish passage tombs, and Iberian schist plaques. We argue that making plaques simultaneously enacts constancy and change for the Neolithic communities of the Isle of Man. The plaques are not symptomatic of the distinctiveness of the Manx Neolithic; they forge the relationships and connections that make the Isle of Man distinctive.

\section{CONCLUSION}

The notion of multiple objects seems counterintuitive when first encountered. We are familiar with a Euro-American ontology that divides inert objects from active subjects. The notion of the cultural biography of artefacts clearly perpetuates this ontological division: inert artefacts travel through different sets of cultural contexts that bestow cultural values upon them. Instead, by arguing that objects are constituted by multiple practices, the properties of materials play an important role in how those practices are enacted and played out (see also Conneller [2011] for a wider discussion of this point), and it is recognised that these materials are unstable and change over time as they are interacted with; this is what makes them multiple. Like the concept of cultural biography, the notion of multiplicity - and multiple objects - places emphasis on relational networks, but these networks are not only composed of human relationships, they are composed of connections between a host of forces: human and non-human. We use the term 'ontographic' (see Holbraad 2009) to describe this kind of approach. To analyse artefacts 'ontographically' is to examine how they enact different relationships as they change over time; it is to place emphasis on the changing constitution of materials as they are altered and participate in differing networks of relationships.

In addition to retaining a distinction between active subjects and inert objects, the biographical approach also retains a sense of linearity: objects undergo a succession of phases of change. To discuss the notion of multiple objects is to emphasise that objects are involved in a multiplicity of relationships, some of which may alter the ontological character of the object. Critically these relationships may occur at the same time, and need not occur successively. This shifts our emphasis from a biographical approach in which we have some fixed points (in the form of artefacts) and a series of relationships to an approach that emphasises multiplicity in which there are no fixed points, only relationships. The properties of both things and people emerge from these relationships. The specific character of these properties will depend upon the set of relationships they are involved in, as well as the processes that brought these relational components together (De Landa 2011, p. 185). Our task then shifts from a biographical one in which we examine the changing history of certain entities with fixed properties (i.e. artefacts) to an approach emphasising multiplicity that instead accounts for how and why properties emerge and endure over time.

If we focus our analysis on relationships it is apparent that all objects simultaneously act and are enacted; all objects are multiple. But some objects are more multiple than others: they are composed of denser and more complex networks of relationships. The Manx 
plaques that form the focus of this article highlight the multiplicity of relationships which artefacts may elicit. Precisely because of their shifting character, they offer excellent examples of multiple objects.

\section{ACKNOWLEDGEMENTS}

The authors gratefully acknowledge the receipt of Leverhulme Trust grant RPG-2014-193 for the project entitled 'Making a Mark: Imagery and Process in the Neolithic of Britain and Ireland' to carry out this project. They would especially like to thank Allison Fox, curator at the Manx Museum, who facilitated the analysis of the Manx plaques, and Katie Barrs who willingly answered Rachel's many questions about stone axes. In addition, the authors would like to thank Adam Gwilt, curator at the National Museum of Wales, Cardiff, for his immense patience and helpfulness.

\section{DISCLOSURE STATEMENT}

No potential conflict of interest was reported by the authors.

\section{FUNDING}

This work was supported by the Leverhulme Trust [RPG-2014-193].

\section{REFERENCES}

Appadurai, A., 1986. Introduction: commodities and the politics of value. In: A. Appaduarai, ed. The social life of things. Cambridge: Cambridge University Press, 3-63.

Barrs, K., 2010. Manx stone axehead project. Thesis (MA). University of Liverpool.

Bersu, G., 1947. A cemetery of the Ronaldsway culture at Ballateare, Jurby, Isle of Man. Proceedings of the Prehistoric Society, 13, 161169. doi:10.1017/S0079497X0001968X

Bradley, R., and Edmonds, M., 1993. Interpreting the axe trade: production and exchange in Neolithic Britain. Cambridge University Press: Cambridge.

Bradley, R., et al., 2001. Decorating the houses of the dead: incised and pecked motifs in
Orkney chambered tombs. Cambridge Archaeological Journal, 11, 45-67. doi:10.1017/ S0959774301000038

Breuil, H., 1934. Presidential address to the Prehistoric Society of East Anglia, 1934. Proceedings of the Prehistoric Society of East Anglia, 7 (03), 289-322. doi:10.1017/ S0958841800026831

Bruce, J.R., Megaw, E.M., and Megaw, B.R.S., 1947. A Neolithic site at Ronaldsway, Isle of Man. Proceedings of the Prehistoric Society, 13, 139-160. doi:10.1017/S0079497X00019678

Burrow, S., 1997. The Neolithic culture of the Isle of Man: A study of the sites and pottery. BAR British Series, 263. BAR: Oxford.

Burrow, S., 1999. The Ronaldsway pottery of the Isle of Man: a study of production, decoration, and use. Proceedings of the Prehistoric Society, 65, 125-143. doi:10.1017/S0079497X00001961

Burrow, S., and Darvill, T., 1997. AMS dating of the Manx Ronaldsway Neolithic. Antiquity, 71 (272), 412-419. doi:10.1017/S0003598X0008501X

Burström, N.M., 2014. Things in the eye of the beholder: a humanistic perspective on archaeological object biographies. Norwegian Archaeological Review, 47 (1), 65-82. doi:10.1080/00293652.2014.909877

Chapman, J., 2000. Fragmentation in archaeology: people, places and broken objects in the prehistory of South-Eastern Europe. London: Routledge.

Clark, J.G.D., 1935. The prehistory of the Isle of Man. Proceedings of the Prehistoric Society, 1, 70-92. doi:10.1017/S0079497X00022192

Cochrane, A., 2009. Additive subtraction: addressing pick dressing in Irish passage tombs. In: J. Thomas and V. Olivera Jorge, eds. Archaeology and the politics of vision in a post-modern context. Cambridge: Cambridge Scholars Publishing, 163-185.

Conneller, C., 2011. An archaeology of materials: substantial transformations in early prehistoric Europe. London: Routledge.

Crellin, R., 2014. Changing times: the emergence of a bronze age on the Isle of Man. Thesis (PhD). University of Newcastle.

Cultural Heritage Imaging, 2011. Reflectance Transformation Imaging: Guide to Highlight Image Processing v1.4. San Francisco: Cultural Heritage Imaging. Available at: <http://cultural heritageimaging.org/What_We_Offer/Down loads/rtibuilder/RTI_hlt_Processing_Guide_v14_ beta.pdf $>$ (last accessed: 28/09/2016). 
Cultural Heritage Imaging, 2013a. Reflectance Transformation Imaging: Guide to Highlight Image Capture v2.0. San Francisco: Cultural Heritage Imaging. Available at: <http://cultural heritageimaging.org/What_We_Offer/Down loads/RTI_Hlt_Capture_Guide_v2_0.pdf> (last accessed: 28/09/2016).

Cultural Heritage Imaging, 2013b. Guide to RTIViewer $v$ 1.1. San Francisco: Cultural Heritage Imaging. Available at: <http://cultural heritageimaging.org/What_We_Offer/ Downloads/rtiviewer/RTIViewer_Guide_v1_1. pdf> (last accessed: 28/09/2016).

Darvill, T., and Andrews, K., 2014. Polychrome pottery from the Later Neolithic of the Isle of Man. Cambridge Archaeological Journal, 24 (3), 531-541. doi:10.1017/S095977431400078X

Darvill, T., et al., 2005. The Cronk yn How stone and the rock art of the Isle of Man. Proceedings of the Prehistoric Society, 71, 283-331. doi:10.1017/S0079497X00001043

De Landa, M., 2011. Philosophy and simulation: the emergence of synthetic reason. Bloomsbury: London.

Díaz Guardamino, M., 2015. Stones in movement: tracing the itineraries of Menhirs, Stelae, and Statue-Menhirs in Iberian landscapes. In: R. Joyce and S.D. Gillespie, eds. Things in motion: object itineraries in anthropological practice. Santa Fe: SAR Press, 101-122.

Eogan, G., 1986. Knowth and the passage tombs of Ireland. London: Thames and Hudson.

Eogan, G., 1997, Overlays and underlays: aspects of megalithic art succession at Brugh na Boinne, Ireland. Brigantium, 10, 217-234.

Fowler, C., 2004. The archaeology of personhood: an anthropological approach. London: Routledge.

Garrad, L., 1984. Rescue excavations 1980-1982: Ballavarry. Proceedings of the Isle of Man Natural History and Antiquarian Society, 9 (2), 163-168.

Gonçalves, V.S., 1999. Reguengos de Monsaraz, territórios megalíticos. Lisboa: Câmara Municipal de Reguengos de Monsaraz.

Gonçalves, V.S., 2008. Na Primeira Metade do 3 Milenio A.N.E dois subsistemas magico-religiosos no centro e sul de Portugal. In: M.S. Hernández Pérez, J.A. Soler Díaz, and J.A. López Padilla, eds. IV Congreso del Neolítico Peninsular. Alicante: Museo de Arqueológico Alicante, 112-120.
Gonçalves, V.S., Andrade, M., and Pereira, A., 2005a, As placas de xisto gravadas das grutas artificiais do Tojal de Vila Chã (Carenque) e da necrópole das Baútas (Mina, Amadora). $O$ Archeologo Portugués, 22, 113-162.

Gonçalves, V.S., Pereira, A., and Andrade, M., 2003, A propósito do reaproveitamento de algumas placas de xisto gravadas da região de Évora. O Archeologo Portugués, 21, 209-244.

Gonçalves, V.S., Pereira, A., and Andrade, M., 2005b. As notáveis placas votivas da Anta de Cabacinhitos (Évora). Revista Portuguesa De Arqueología, 8 (1), 43-109.

Gosden, C., and Marshall, Y., 1999. The cultural biography of objects. World Archaeology, 31 (2), 169-178. doi:10.1080/00438243.1999.9980439

Grimes, W.F., 1939. Guide to the Prehistoric Collections. Cardiff: National Museum of Wales.

Hallgren, F., 2008. Identitet i pratikk: Lokal, regional och överregionala sociala sammanhang innom nordlig trattbägerkultur. Uppsala: Department of Archaeology and Ancient History, Uppsala University.

Hallgren, F., 2012. A permeable border: long distance contacts between hunters and farmers in the Early Neolithic of Scandinavia. In: C. Damm and J. Saarikivi, eds. Networks, interaction and emerging identities in Fennoscandia and beyond. Mémoires de la Société FinnoUgrienne, 265. Helsinki: The Finno-Ugrian Society, 139-154.

Hawkes, C.F.C., 1941. Engraved plaques from the Bann Diatomite. Ulster Journal of Archaeology, IV (1941), 19-22.

Herity, M., 1974. Irish passage graves: Neolithic tomb builders in Ireland and Britain, 2500 BC. Dublin: Irish University Press.

Hinchliffe, S., 2010. Working with multiples: a non-representational approach to environmental issues. In: B. Anderson and P. Harrison, eds. Taking-place: non-representational theories and geography. Farnham: Ashgate, 303-320.

Holbraad, M., 2009. Ontology, ethnography, archaeology: an afterword on the ontography of things. Cambridge Archaeological Journal, 19 (3), 431-441. doi:10.1017/S0959774309000614

Holtorf, C., 2008. The life history approach to monuments. An obituary? In: J. Goldhahn, ed. Gropar og monument: En vänbok till Dag Widholm. Kalmar Studies in Archaeology IV. Kalmar: University of Kalmar, 411-427. 
Hoskins, J., 1998. Biographical objects: how things tell the stories of peoples' lives. London: Routledge.

Ingold, T., 2007. Materials against materiality. Archaeological Dialogues, 14, 1-16. doi:10.1017/S1380203807002127

Ingold, T., 2011. Being alive: essays on movement, knowledge and description. Routledge: London.

Jones, A., 2004. By way of illustration: art, memory and materiality in the Irish Sea and beyond. In: V. Cummings and C. Fowler, eds. The Neolithic of the Irish Sea: materiality and traditions of practice. Oxford: Oxbow, 202-213.

Jones, A., 2005. Lives in fragments? Personhood and the European Neolithic. Journal of Social Archaeology, 5 (2), 193-224. doi:10.1177/ 1469605305053367

Jones, A.M., 2012. Prehistoric materialities: becoming material in Prehistoric Britain and Ireland. Oxford: Oxford University Press.

Jones, A.M., Forthcoming. The art of assemblage: styling Neolithic art. Cambridge Archaeological Journal.

Joy, J., 2009. Reinvigorating object biography: reproducing the drama of object lives. World Archaeology, 41 (4), 540-556. doi:10.1080/ 00438240903345530

Joyce, R., 2015. Things in motion: itineraries of Ulua marble vases. In: R. Joyce and S.D. Gillespie, eds. Things in motion: object itineraries in anthropological practice. Santa Fe: SAR Press, 21-38.

Joyce, R., and Gillespie, S.D., 2015. Making things out of objects that move. In: R. Joyce and S.D. Gillespie, eds. Things in motion: object itineraries in anthropological practice. Santa Fe: SAR Press, 3-20.

Kopytoff, I., 1986. The cultural biography of things. In: A. Appaduarai, ed. The social life of things. Cambridge: Cambridge University Press, 64-91.

Latour, B., 1993. We have never been modern. London: Harvard University Press.

Lillios, K., 2008. Heraldry for the Dead: memory, identity, and the engraved stone plaques of Neolithic Iberia. Austin: The University of Texas Press.

Malzbender, T., Gelb, D., and Wolters, H., 2001. Polynomial texture maps: proceedings of the 28 th annual conference on computer graphics and interactive techniques (SIGGRAPH '01). New York: ACM, 519-528.
Malzbender, T., et al., 2004. Enhancement of shape perception by surface reflectance transformation: proceedings of vision, modeling, and visualization 2004, November 16-18, 2004 , Standford, USA. Stanford: IOS Press.

Mol, A.-M., 2002. The body multiple: ontology in medical practice. Durham: Duke University Press.

Mol, A.-M., 2006. Cutting surgeons, walking patients: some complexities involved in comparing. In: J. Law and A.-M. Mol, eds. Complexities: social studies of knowledge practices. Durham: Duke University Press, 218-257.

Mudge, M., Malzbender, T., Schroer, C., \& Lum, M., 2006. New Reflection Transformation Imaging Methods for Rock Art and MultipleViewpoint Display. In: I. Ioannides, D. Arnold, F. Niccolucci, and K. Mania, eds. VAST 2006: Proceedings of the 7th International Symposium on Virtual Reality, Archaeology and Cultural Heritage, Nicosia, Cyprus, 2006, 195-202.

O’Sullivan, M., 1986, Approaches to passage tomb art. Journal of the Royal Society of Antiquaries of Ireland, 116, 68-83.

O’Sullivan, M., 1996. Megalithic art in Ireland and Brittany: divergence or convergence? In: J. L'Helgouach, C.-T. Le Roux, and J. Lecornce, eds. Art et symboles du mégalithisme Européen. Rennes: Revue Archéologique de l'Ouest, Supplement 8, 81-96.

Oliveira, J., 1993, Reutilizações e reaproveitamentos de materiais em sepulturas megalíticas do Nordeste Alentejano. Trabalhos de Antropologia e Etnologia, Porto, 33, 132-144.

Olsen, B., 2003. Material culture after text: re-membering things. Norwegian Archaeological Review, 36, 87-104. doi:10.1080/00293650310000650

Olsen, B., 2010. In defense of things: archaeology and the ontology of objects. Lanham: Altamira Press.

Piggott, S., 1954. Neolithic cultures of the British Isles. Cambridge: Cambridge University Press.

Schiffer, M.B., 1972. Archaeological context and systemic context. American Antiquity, 37 (2), 156-165. doi:10.2307/278203

Schiffer, M.B., 1976. Behavioural archaeology. New York: Academic Press.

Shanks, M., 1998, The life of an artifact. Fennoscandia Archaeologica, 15, 15-42.

Strathern, M., 1988. The gender of the gift: problems with women and problems with society in Melanesia. Berkeley: University of California Press. 
Thomas, J., 1996. Time, Culture and Identity: an interpretative archaeology. London: Routledge.

Thomas, J., 2000. Death, identity and the body in Neolithic Britain. Journal of the Royal Anthropological Institute, 6, 653-668. doi:10.1111/1467-9655.00038
Tilley, C., 1996. An ethnography of the Neolithic. Cambridge: Cambridge University Press.

Warren, H.S., 1921, Excavations at the stone-axe factory of Graig Lwyd, Penmaenmawr. Journal of the Royal Anthropological Institute, 1921, 165-199. 